\title{
Heart failure with improved ejection fraction: A review and pooled analysis of pathophysiology, diagnosis and clinical management
}

\author{
Aref Albakri* \\ St-Marien hospital Bonn Venusberg, department of internal medicine, Bonn, Germany
}

\begin{abstract}
Substantial or even complete myocardial healing may occur in patients with heart failure (HF) either after aggressive treatment or after the removal of the causative agent. This cohort has been termed HF with improved left ventricular (LV) ejection fraction (HFiEF) and they are prevalent in the HF referral population. They are a distinct cohort of $\mathrm{HF}$ patients with different underlying causes, comorbidities, response to therapy and outcomes compared to HF patients with persistently reduced ejection fraction ( $\mathrm{HFrEF}$ ) or with preserved ejection fraction ( $\mathrm{HFpEF})$. LVEF has been the mainstay of measuring therapeutic success and prognosis in $\mathrm{HF}$ patients. Improvements in LVEF suggest effectiveness of therapy and better quality of life as well as lower hospitalization rates and longer survival. However, mortality and morbidity in HFiEF patients remains higher compared to those in the normal population (those that have never had HF) suggesting that recovery of LVEF may not necessarily translate into true healing. Moreover, clinical management of these patients is challenging because of the lack of consensus guidelines or data to guide management and whether to continue or discontinue treatment after LVEF recovery is an individual centre's decision. This paper reviews specific clinical features, pathophysiology, and clinical implications for HFiEF to improve clinical understanding of this new HF phenotype.
\end{abstract}

\section{Introduction}

In the mid-1980s, studies of vasodilator therapy in patients with heart failure (HF) with reduced left ventricular (LV) ejection fraction (LVEF) begun to report that LVEF can improve in the course of guideline-directed HF therapy [1]. With advancements in medical and device therapies of $\mathrm{HF}$ with reduced $\mathrm{EF}$ (HFrEF), studies have repeatedly identified a subset of HF patients with substantial improvement in LVEF with or without therapy [2]. With these discoveries, HF with improved ejection fraction (HFiEF) has been recently introduced for patients with a normalized LVEF but who previously had reduced LVEF. The conundrum is whether improved fraction (EF) means a true healing (reverse modelling) of the LV systolic function or it is simply a normalization of the LVEF. Underlying the conundrum is the observation that many HFiEF patients continue to exhibit remaining abnormalities such as elevated biomarker profiles, and high hospitalization and mortality rates compared to individuals who have never had HF. In some HFiEF patients, improvement may be transient suggesting that the presence of other factors may mediate recovery and the recurrence of reduced LVEF. Besides, there are no tested or validated treatment regimens for this population.

The decision to continue or to stop HF treatment upon LVEF improvement has remained a grey area in HF literature and cardiology practice. The current HF guidelines on treatment of $\mathrm{HF}$ by the European Society of Cardiology (ESC) [3,4], the American Heart Association (AHA) [5] and Canadian Cardiovascular Society [6] are all silent on clinical management of HFiEF patients. These guidelines only give recommendations for the diagnosis and management of HF with reduced $\mathrm{EF}(\mathrm{HFrEF})$ and $\mathrm{HF}$ with preserved $\mathrm{EF}$ (HFpEF). The emerging question on the management of HFiEF patients are. (a) Should these patients remain on HF treatment regimen they used when they had reduced EF? (b) Should they be treated using recommendations for HFpEF patients? (c) Is there another viable HF treatment option for HFiEF patients? (d) How often should these patients be evaluated for changes on LVEF? To answer these questions and many others, this paper reviews current published evidence on HFiEF patients to develop an understanding of its prevalence, risk factors, treatment and prognosis.

\section{Nomenclature}

The primary function of the heart is pumping blood through the entire circulation system to meet the hematologic needs of all body cells. Ejection fraction (EF) is a widely used clinical parameter and the mainstay of measuring the pumping efficiency of the heart. A heart that cannot pump sufficient blood to meet the hematologic needs of cells will often exhibit a lower EF. Thus, EF is an important indicator of the pumping efficiency of the heart and the cornerstone for the definition, classification and treatment of HF. The EF of the left heart, known as LVEF, is a volumetric fraction of the blood ejected from the left side of the heart with each contraction. It is calculated by dividing stroke volume (the volume of blood ejected from the LV per beat) by the end-diastolic volume (volume of blood collected in the LV at the end of diastolic filling). The EF of the right heart, known as the RVEF, measures the pumping efficiency of the heart into the pulmonary

${ }^{\star}$ Correspondence to: Aref Albakri, St-Marien hospital Bonn Venusberg, department of internal medicine, Bonn, Germany, E-mail: arefalbakri@yahoo.com

Key words: heart failure [hf], heart failure with improved ejection fraction [hfief], heart failure with recovered ejection fraction; heart failure with reduced ejection fraction [hfref]

Received: May 03, 2020; Accepted: May 15, 2020; Published: May 22, 2020 
circulation. In clinical practice, the RVEF is the most common index used for measuring RV contractility. However, its utility in the clinical diagnosis of HF is limited because it is highly dependent on loading condition and therefore may not adequately reflect contractility [7].

After the vasodilator studies of HFrEF patients in the mid-1980s revealed a subset of HF patients with improved LVEF (HFiEF), several subsequent studies have supported structural and functional improvement of the LV with or without therapy [8-12]. However, HFiEF patients lack a consensus definition because the available guidelines provide different description and categorization. The most recent 2013 American College of Cardiology Foundation/American Heart Association (ACCF/AHA) guidelines for the management of HF describes a cohort of HFpEF improved as those having LVEF $>40 \%$ but who previously had LVEF $\leq 40 \%$ [5]. The 2016 ESC position statement for the diagnosis and treatment of HF introduced a category they termed HF with midrange EF (HFmEF) with LVEF ranging between $40 \%$ and $49 \%$ but did not distinguish between patients who previously had lower LVEF and those who have never had reduced LVEF $(\leq 40 \%)$. Other studies have described HFiEF patients as those who have LVEF $\geq 50 \%$ but with previously documented LVEF $<50 \%[9,13]$. HFiEF has since been described as HF patients with LVEF $>40 \%$ with a previously documented LVEF $<35 \%$ and have experienced an improvement in LVEF $>10 \%$, which is beyond reproducibility and variability of imaging techniques $[14,15]$.

Besides HFiEF, other terminologies of this HF subset have been proposed such as HF with recovered EF, HF with restored EF or HF with better EF. However, the terminology HFiEF (improved EF) is more practical than recovered or restored EF. Improved EF means that despite having normalized LVEF, patients may continue to exhibit clinical symptoms of $\mathrm{HF}$ and abnormal biomarker signs of cardiac functional impairment. The term "improved LVEF" also does not necessarily mean recovery from the underlying structural changes to cardiac structure and function. HFiEF also acknowledges the existence of varying degrees of improvement, and the magnitude of change can have prognostic implications [15]. Besides, improvement in LVEF has been considered a surrogate marker for the underlying process of reverse remodelling at the myocardial and ventricular structural and functional levels, and therefore, should accompany a decrease in LV volumes [16].

\section{Epidemiology \\ HF referral population}

A wide heterogeneity of aetiologic agents of the clinical syndrome of HF complicates the accurate determination of the epidemiology of HFiEF as well as the conduct of epidemiological studies on this HF patient sub-population. The prevalence of HFiEF varies significantly across different aetiologies of $\mathrm{HF}$ as well as varies based on spontaneous recovery of LVEF after the withdrawal of the causative agent or after undergoing aggressive medical therapy. For patients with Takotsubo (stress) cardiomyopathy (CM), LVEF improvement can occur rapidly even in the absence of medical therapy [17-19]. For many other HF patients, recovery of LVEF may be partially or wholly the result of aggressive medical therapy. Thus, the frequency of LVEF improvement depends on the aetiologic agent of the underlying CM or other heart diseases.

In an epidemiological study on the recovery of LVEF, Givert et al. [20] reported rates of LVEF improvement to $>50 \%$ of between $60 \%$ and $100 \%$ in various reversible aetiologies of a recent onset (less than 6 months) dilated cardiomyopathy (DCM) such as tachycardia, Takotsubo and hyperthyroidism. However, lower rates of LVEF improvement were observed in patients with chronic HF. In Basuray et al. [9] post-hoc study on a cohort of 1,821 HF patients of the Penn Heart Failure Study, only $10 \%$ had improved LVEF to $\geq 50 \%$. In a related post-hoc study evaluating 4,500 HF subjects enrolled in the Valsartan Heart Failure Trial (Val-HeFT), Florea et al. [14] reported only 9\% improved LVEF to $\geq 40 \%$ during the 12 months follow-up period.

\section{Recipients of device therapy}

The prevalence of HFiEF also varies in patients receiving device therapy for HF. In the Multicentre Automatic Defibrillator Implantation Trial with Cardiac Resynchronization Therapy (MADIT-CRT) 79\% of the patients had partial LVEF improvement to an average of $36 \%$ to $50 \%$ from a baseline of $30 \%$. Only $7.3 \%$ of the patients had significant improvement in LVEF to $>50 \%$ [21]. In studies enrolling smaller HF cohorts implanted with CRT, a significant improvement in LVEF occurred in between $12 \%$ and $17 \%$ [22,23]. Substantial improvement in LVEF among HF patients who have undergone CRT suggests that unlike other HFrEF patients, LV dyssynchrony is a dominant cause of impaired LV function. The current evidence on epidemiology of HFiEF supports that the frequency of LVEF normalization varies considerably due to differences in definition of HFiEF as well as in the heterogeneity of study populations in terms of HF origin, duration and underlying medical therapy [15].

\section{A meta-analysis of HFiEF studies}

A meta-analysis of HFiEF studies is complicated by a wide variability in aetiology, duration of HF and medical treatment evaluated in different studies. Ideal meta-analysis should only include studies that enrol patients with a recent onset of HFrEF because in these patients, the initiation of guideline-directed HF regimen would provide an accurate assessment of the changes in LVEF. However, due to limited studies, both prospective and retrospective studies were included and formed the final dataset for analysis. Table 1 provides of the main study and patients characteristics of the included studies.

The present systematic review and meta-analysis included fourteen (14) observational studies published between 2001 and 2019. Due to the recency of HFiEF, most of the available studies compared characteristics, prognosis and clinical management of HFiEF patients with HFrEF and/or HFpEF patients. The 14 studies comprised of an equal number of prospective studies [9,14,24-33] and retrospective studies $[2,11,24,27,29,30,32]$. Half $(50 \%)$ of the studies were performed in the United States $[2,9,25,27,28,30,32]$, three in Spain $[11,29,31]$, and one each in Italy [24], France [26], and Korea [33], while the remaining one was an international study [14]. In total, the 14 studies enrolled 16,632 patients with chronic HF from tertiary clinics, referral to HF units, ambulatory patients, hospitalized patients, patients in tertiary clinics. HF registry and outpatients. Patients excluded were those without documented LVEF six months prior to the study, and without a follow-up LVEF in retrospective studies, which enabled the determination and classification of patients based on changes in LVEF.

\section{Patient characteristics}

Of the 16,632 HF patients enrolled in the 14 studies, 3,767 were HFiEF patients accounting for $22.7 \%$ of the study population. They were fewer than HFrEF patients accounting for $61.8 \%(n=10,285)$ of the study population but more than HFpEF patients accounting for 
Table 1. Characteristics of included studies

\begin{tabular}{|c|c|c|c|c|c|c|c|}
\hline $1^{\text {st }}$ Author [Ref \#] & Year & Country & Design & Patient Population & Sample & $\begin{array}{l}\text { Definition of } \\
\text { LVEF }\end{array}$ & Predictors of LV Recovery \\
\hline Cicoira $[24]$ & 2001 & Italy & Retrospective & Chronic HF (iDCM) & 98 & $\geq 40 \%$ & $\begin{array}{l}\text { Men, older, \& NICM and on ACE-I/ARB \& } \\
\beta \text {-blocker }\end{array}$ \\
\hline Punnoose [2] & 2011 & US & Retrospective & $\begin{array}{l}\text { Clinical Diagnosis } \\
\text { of } \mathrm{HF}\end{array}$ & 358 & $\geq 40 \%$ & Young age, less AF, hypertension, and DM \\
\hline Wilcox [25] & 2012 & U.S. & Prospective & Improve HF Trial & 2709 & $>10 \%$ increase & $\begin{array}{l}\text { Female sex, no prior MI, non-ischemic HF } \\
\text { aetiology, and no digoxin use }\end{array}$ \\
\hline Basuray [9] & 2014 & U.S & Prospective & $\begin{array}{c}\text { HF patients in tertiary } \\
\text { clinics }\end{array}$ & 1821 & $\geq 50 \%$ & Abnormal biomarker profile - troponin I \\
\hline De Groote [26] & 2014 & France & Prospective & $\begin{array}{c}\text { Chronic HF on } \\
\beta \text {-blocker }\end{array}$ & 174 & $\geq 45 \%$ & $\begin{array}{l}\text { Negative predictors are high LVEDD, low heart rate } \\
\text { and the presence of complete LBBB }\end{array}$ \\
\hline Florea [14] & 2016 & International & Prospective & $\mathrm{HF}$ from Val-HeFT & 3519 & $>40 \%$ & $\begin{array}{c}\text { Less severe hemodynamic, biomarker, and } \\
\text { neurohormonal profile, higher BP and } \beta \text {-blocker or } \\
\text { valsartan }\end{array}$ \\
\hline Kalogeropoulos [27] & 2016 & U.S & Retrospective & $\begin{array}{l}\text { Adult outpatient } \\
\text { with HF }\end{array}$ & 2166 & $>40 \%$ & $\begin{array}{c}\text { Young age, male, less likely to have coronary artery } \\
\text { disease, DM, and kidney disease and taking ACEI/ } \\
\text { ARB }\end{array}$ \\
\hline Nadruz [28] & 2016 & U.S & Prospective & $\begin{array}{l}\text { HF patients referred } \\
\text { to CPET }\end{array}$ & 837 & $>40 \%$ & Use of $\beta$-blockers and ACEI/ARB \\
\hline Trulas [29] & 2016 & Spain & Retrospective & Spanish HF Registry & 1202 & $\geq 50 \%$ & $\begin{array}{c}\text { Young age, } \\
\text { NYHA II-III, lower prevalence of DM, dementia } \\
\text { and cerebrovascular disease, higher } \\
\text { prevalence of COPD }\end{array}$ \\
\hline Adamo $[30]$ & 2017 & US & Retrospective & $\begin{array}{l}\text { HD patients with } \\
\text { LVEF }<50 \%\end{array}$ & 96 & $\begin{array}{l}>10 \% \text { increase } \\
\quad>50 \%\end{array}$ & $\begin{array}{l}\text { Normal GLS }(>16) \text { - Men, older, \& NICM and } \\
\text { receiving ACE-I/ARB \& } \beta \text {-blocker }\end{array}$ \\
\hline Lupon $[31]$ & 2017 & Spain & Prospective & $\begin{array}{l}\text { Ambulatory HF } \\
\text { patients }\end{array}$ & 1057 & $\geq 45 \%$ & $\begin{array}{l}\text { Men with } \\
\text { ischaemic HD, older age, NYHA II-III,, non- } \\
\text { ischemic aetiology }\end{array}$ \\
\hline Bermejo [11] & 2018 & Spain & Retrospective & Referral to HF Unit & 449 & $>40 \%$ & $\begin{array}{l}\text { Younger age NYHA II-III, treatment with RAAS } \\
\text { inhibitors and } \beta \text {-blockers, absence }\end{array}$ \\
\hline Swat [32] & 2018 & U.S. & Retrospective & $\begin{array}{l}\text { Hospitalized NICM } \\
\text { Patients }\end{array}$ & 166 & $\begin{array}{l}\geq 40 \% \& \geq 10 \% \\
\text { improvement }\end{array}$ & Normal GLS, smaller LVEDD and LVESD \\
\hline Park [33] & 2019 & Korea & Prospective & $\begin{array}{l}\text { Hospitalized for } \\
\text { Acute HF }\end{array}$ & 1980 & $\geq 50 \%$ & $\begin{array}{c}\text { Younger age, female sex, de novo HF, hypertension, } \\
\text { AF and } \beta \text {-blocker }\end{array}$ \\
\hline
\end{tabular}

ACEI/ARB: Angiotensin converting enzyme - inhibitor/Angiotensin Receptor Blocker; AF: Atrial Fibrillation; DM: Diabetes Mellitus; GLS: Global Longitudinal Strain; HD: Heart Disease; HF: Heart Failure; iDCM: Idiopathic Dilated Cardiomyopathy; LBBB: Left Bundle-Branch Block; LVEDD: Left Ventricular End Diastolic Diameter; LVEF: Left Ventricular Ejection Fraction; MI: Myocardial Infarction; NICM: Non-Ischemic Cardiomyopathy; RAAS: Renin-Angiotensin-Aldosterone System

$15.5 \%(\mathrm{n}=2,580)$. HFiEF patients were younger (59.5 years), compared to HFpEF (69.8 years) and HFrEF (62.2 years). HFiEF patients had a male preponderance $(64.4 \%)$ similar to HFrEF patients $(73.9 \%)$ but HFpEF patients had a female predominance (54.3\%). The mean improvement in LVEF varied considerably between studies attributable to definitional differences (cut-off value for HFiEF patients ranged from $>40 \%$ to $>50 \%$ or an increase of 10 percentage points), the heterogeneity of the study population, aetiologic agents, duration of $\mathrm{HF}$ and underlying medical therapy. In the follow up period, HFiEF patients had a statistically significance weighted mean improvement of 20.86 percentage points ( $95 \%$ CI: 16.86 to 24.85 ; $\mathrm{p}=0.000$; Figure 1). HFiEF patients also had a significant weighted mean decrease in LV end diastolic diameter (LVEDD) of $-11.573 \mathrm{~mm}$ (95\% CI -24.11 to $-0.97 ; \mathrm{p}=0.07)$. HFiEF patients had more often a non-ischemic aetiology (69.14\%) compared to HFrEF (58.16\%).

Besides demographic characteristics, individual studies reported differences in clinical features of HFiEF patients compared to HFrEF and/or HFpEF patients. HFiEF patients are young at age, have shorter duration of HF, de novo onset of HF and less adverse myocardial remodeling at initial evaluation $[2,24,33]$. HFiEF patients also have normal global longitudinal strain (GLS > 16), smaller LV end diastolic or systolic diameter (LVEDD or LVESD) [30,32]. HFiEF patients had fewer comorbidities such as coronary artery disease (CAD), diabetes mellitus, and kidney disease, no prior myocardial infarction (MI), and less severe NYHA functional status - NYHA II-III [11,25,27,29].
Most HFiEF patients are also on beta-blocker or ACE-I/ARB therapy $[11,24,28,30]$. HFiEF patients are also associated with the absence of systemic diseases such as dementia, cerebrovascular disease and higher prevalence of chronic obstructive pulmonary disease (COPD) [27].

\section{Predictors of LVEF improvement}

Despite notable differences in the definition of HFiEF based on LVEF cutoff values across studies $(>40 \%,>45 \%,>50 \%$, or an increase $>$ $10 \%)$, several patient and clinical characteristics at index admission have been identified that may predict the likelihood of LVEF improvement. Unfortunately, studies on HFiEF have investigated a wide variety of demographic and clinical features making the conduct of a metaanalysis impossible. Data could only be pooled from two or three studies assessing similar characteristics that may predict improvement of LVEF in HF patients (Table 2). Patient characteristics at index admission associated with reduced likelihood for LVEF improvement include the male gender (odds ratio [OR] 0.727; $\mathrm{p}=0.000$ ) [14,32,33], and older age $(\mathrm{OR}=0.98 ; \mathrm{p}=0.000)[24,32,33]$. Clinical characteristics with a negative predictive power of LVEF improvement are NYHA functional class III-IV $(\mathrm{OR}=0.422 ; \mathrm{p}=0.024)$ [11], ischemic origin $(\mathrm{OR}=0.479$; $\mathrm{p}=0.000)[11,14,33]$. Positive predictive factors, those associated with the likelihood of a greater LVEF improvement are normal GLS $(>16$ : $\mathrm{OR}=1.226 ; \mathrm{p}=0.001)[30,32]$, the presence of hypertension $(\mathrm{OR}=1.40$; $\mathrm{p}=0.003)[24,33]$ and the use of beta-blocker at discharge $(\mathrm{OR}=1.578$; $\mathrm{p}=0.021)[14,33]$. Individual studies have also reported de novo onset 
LVEF: Difference in means and $95 \% \mathrm{Cl}$

\begin{tabular}{|c|c|c|c|c|c|c|c|c|}
\hline \multirow[t]{2}{*}{ Study name } & \multicolumn{4}{|c|}{ Statistics for each study } & \multicolumn{4}{|c|}{ Difference in means and $95 \% \mathrm{Cl}$} \\
\hline & $\begin{array}{l}\text { Difference } \\
\text { in means }\end{array}$ & $\begin{array}{c}\text { Lower } \\
\text { limit }\end{array}$ & $\begin{array}{c}\text { Upper } \\
\text { limit }\end{array}$ & p-Value & & & & \\
\hline Wilcox [25] & 21.700 & 21.211 & 22.189 & 0.000 & & & & \\
\hline Basuray [9] & 29.000 & 27.809 & 30.191 & 0.000 & & & & \\
\hline De Groote [26] & 21.000 & 19.268 & 22.732 & 0.000 & & & & \\
\hline Florea [14] & 17.800 & 16.934 & 18.666 & 0.000 & & & & \\
\hline Kalogeropoulos [27] & 25.000 & 23.952 & 26.048 & 0.000 & & & & \\
\hline Nadruz [28] & 2.000 & 0.497 & 3.503 & 0.009 & & & & \\
\hline Trulas [29] & 21.000 & 17.137 & 24.863 & 0.000 & & & & \\
\hline Swat [32] & 24.500 & 21.936 & 27.064 & 0.000 & & & & \\
\hline \multirow[t]{3}{*}{ Park [33] } & 25.700 & 24.873 & 26.527 & 0.000 & & & & \\
\hline & 20.855 & 16.861 & 24.849 & 0.000 & & & & \\
\hline & & & & & -30.00 & -15.00 & 0.00 & 15.00 \\
\hline
\end{tabular}

Heterogeinity: $Q=1015.01 ; \operatorname{df}(Q)=8(p=0.000)$; Inconsistency $(I-S q u a r e d)=99.21 \%$

Figure 1. Difference in lvef mean between baseline and follow-up

Table 2. Predictors of LVEF improvement at index admission

\begin{tabular}{|c|c|c|c|}
\hline Predictor & OR & $\mathbf{9 5 \%}$ CI & P-value \\
\hline Age & 0.980 & $0.971-0.989$ & 0.000 \\
\hline NYHA III-IV & 0.422 & $0.199-0.893$ & 0.024 \\
\hline Male & 0.727 & $0.618-0.856$ & 0.000 \\
\hline Ischemic origin & 0.479 & $0.400-0.574$ & 11 \\
\hline Hypertension & 1.400 & $1.122-1.747$ & 0.000 \\
\hline GLS $>16)$ & 1.226 & $1.083-1.388$ & 0.003 \\
\hline BB at discharge & 1.578 & $1.073-2.323$ & 0.001 \\
\hline
\end{tabular}

of HF $(\mathrm{OR}=2.23 ; \mathrm{p}=0.001)$ [33] with a greater likelihood of LVEF improvement while the presence of diabetes mellitus $(\mathrm{OR}=0.55$; $\mathrm{p}=0.001$ ) [33] with a negative likelihood of LVEF improvement.

The present findings are consistent with the reports of a recent systematic literature review by Gulati and Udelson [15] on predictors of LVEF improvement among HF patients. The review lists female sex, non-ischemic aetiology of HF, shorter duration of HF and less severe cardiac remodeling at initial evaluation as positive predictors of LVEF improvement among HF patients with reduced LVEF. The same factors also predict HF patients that may respond well to CRT. The review also associates the presence of ECG findings such as LBBB with attenuated LVEF improvement or the lack of LVEF improvement for HF patients receiving optimal medical therapy. On the other hand, the authors associate the presence of LBBB with a positive response to CTR therapy, suggesting the relevance of dyssynchrony in the clinical maintenance of LV dysfunction in some patients.

Besides patient and clinical characteristics, genetic involvement in LVEF improvement among HFiEF patients has also been reported. Activating mutation in the angiotensin-converting enzyme or adrenergic receptor genes may attenuate LVEF response to medical therapy [34]. Mutations in the sarcomeric proteins may also be involved in LVEF improvement. HF patients having truncating mutations in the titin-A gene show a higher frequency of LVEF improvement $>10 \%$ compared with HF patients with idiopathic DCM or patients with LMNA mutations treated with guideline-directed therapies [35]. In contrast, patients with peripartum $\mathrm{CM}$ with truncating tintin-A mutation showed reduced likelihood of LVEF normalization at 12 months compared to patients without the same mutations [36].

\section{Mortality and hospitalization}

HFiEF patients also demonstrate significantly reduced rates of cardiovascular mortality and hospitalization for cardiac causes compared to HFrEF and HFpEF patients. From a pooled analysis of data from three studies, HFiEF had significantly lower deaths compared to HFrEF (OR: $0.345 ; 95 \%$ CI: 0.273 to $0.435 ; \mathrm{p}=0.000$ ) and HFpEF (OR: $0.633 ; 95 \%$ CI: 0.497 to $0.807 ; \mathrm{p}=0.000)[11,28,33]$. Three other studies also report a higher mortality rate for HFrEF patients (OR:1.947; 95\% CL: 1.326 to $2.858 ; \mathrm{p}=0.0010$ ) and HFpEF (OR: 1.43 ; 95\% CL: 1.078 to $1.897 ; \mathrm{p}=0.013)[9,11,29]$. Only one study, a retrospective analysis of patients in the CARDIOCHUS-CHOP registry reported significantly higher hospitalization rates among $\mathrm{HFpEF}$ versus $\mathrm{HFiEF}$ patients (Hazard Ratio [HR]: 1,411; 95\% CL: 1.046 to 1.903; $\mathrm{p}=0.024$ ) and HFrEF versus HFiEF patients (HR: 1.388 ; $95 \%$ CL: 1.002 to $1.924 ; \mathrm{p}$ $=0.049$ ) [11]. These findings suggests that HF patients have a lower survival rate and hospitalization rates for cardiac reasons compared to both HFrEF and HFpEF patients.

\section{Clinical presentation and outcomes}

\section{Clinical presentation}

Sufficient data is lacking to provide a complete clinical picture of HFiEF patients after LVEF improvement. Such data would have guided clinical management of these patients. Current reviews describe HFiEF patients relative to HFrEF or healthy controls to determine whether HFiEF can be considered a phenotype of HF. The few available studies suggest that HFiEF patients may have a distinct clinical and biochemical profile from HFrEF and HFpEF patients as well as from the general 
population (those who have never heard HF) [15]. In a cross section study enrolling 358 patients from tertiary care HF center, Punnoose et al. [2] compared HFrEF and HFiEF patients after LVEF improvement. HFiEF patients were younger and less likely to have coronary artery disease compared to HFrEF patients but both cohorts had similar rates of AF, hypertension and diabetes. HFiEF patients exhibited higher systolic blood pressures and smaller LV volumes compared to HFrEF patients. However, HFiEF patients had larger LV volumes compared to HFpEF patients, suggesting the possibility of some degree of residual adverse remodelling despite LVEF improvement.

Besides clinical profile, HFiEF patients also exhibit a distinct biomarker profile. Overall, HFiEF patients have lower serum levels of B-type natriuretic peptide (BNP) and troponin compared to HFrEF patients. However, in about a half of HFiEF patients, the levels of cardiac biomarkers remained elevated suggesting ongoing neurohormonal activation and myocardial stress and injury [9]. HFiEF patients have lower exercise capacity (average peak oxygen consumption at 17-18 $\mathrm{ml} / \mathrm{kg} / \mathrm{min}$ ) compared to healthy controls [28]. Compared to HFrEF patients, HFiEF have better quality of life although $25 \%$ to $75 \%$ still exhibit HF symptoms despite optimal medical therapy $[2,9,28]$. The current evidence suggests that HFiEF patients have a more favourable clinical, biomarker and functional characteristics than HFrEF patients but less favourable than healthy controls. Their phenotypic improvement does not necessarily reflect full recovery from adverse structural remodelling or remission of HF.

\section{Clinical outcomes}

HFiEF patients have favourable clinical outcomes relative to HFrEF and HFpEF patients. Several prospective moderate-sized cohorts of HFiEF have reported higher survival rates of $80 \%$ to $90 \%$ compared to $65 \%$ to $75 \%$ of HFrEF patients $[26,28,31]$. HFiEF patients with normalized LVEF exhibit the most favourable outcomes. Those with partial improvement to between $41 \%$ and $49 \%$ from $<35 \%$ also show better survival rates compared to HFpEF patients with preserved LVEF between $41 \%$ and $49 \%$ [28]. These findings suggests that improvement in LVEF is an independent predictor of improved heart transplantation survival even after accounting for differences in LVEF, HF duration, and beta-blocker treatment at index admission [37]. The findings suggest that reverse remodelling itself may lead to increased survival [38]. However, overall survival of HFiEF patients is lower than in healthy controls [26].

Natural studies of HF show that HFiEF patients are still at a higher risk of developing HFrEF compared to healthy controls. Factors associated with HFrEF recurrence among HFiEF patients include discontinuation of HF therapy, older age, longer HF duration, larger LVEDD, lower LVEF, LBBB, larger LVEDD, slower heart rate, hypertension and lower glomerular filtration rate (GFR) $[26,28,39,40]$. Same to the association of severe LVEF remodelling with reduced rates of LVEF improvement, larger LV diameter is associated with an increased risk of future reduction in LVEF [26,39]. Mechanics for LV deformation may also predict HFiEF patients at a higher risk of developing recurrent HFrEF. A more negative GLS at the time of LVEF improvement increases the risk of future deterioration of LVEF [30]. The mean GLS in the HFiEF patients was $-14.4 \%$, which was lower than the current normal value of $-17 \%$ to $-20 \%$. The association of GLS with future LVEF decline suggests HFiEF patients may remain with subtle but detectable myocardial abnormalities [30]. The presence of LBBB has also been associated with an independent risk for the deterioration of LVEF [26]. Although several risk factors have been linked with increased likelihood a recurrence of LVEF, it remains difficult to predict with accuracy which HFiEF patents may experience HFrEF recurrence.

\section{Mechanisms of HFiEF}

Transforming growth factor beta and endothelin-1 pathway: The precise mechanisms underlying HFiEF remains unclear but available evidence suggests the involvement of neurohormonal and electrical aberrations. The association between continued HF therapy and LVEF improvement suggests the transforming growth factor beta and endothelin-1 (TGF- $\beta 1$ ) pathway that HF therapy targets may provide valuable insights into the mechanisms underlying LVEF improvement. Upregulation of angiotensin II signalling, which mimics neurohormonal activation observed in HFrEF patients may be involved in the deleterious cardiomyocyte hypertrophy mediated by the transforming growth factor beta and endothelin-1 [41]. ACE-I drugs downregulates TGF- $\beta 1$ pathway by suppressing fibroblast signalling and collagen deposition, and in the process inhibit myocardial fibrosis [42].

Beta-adrenergic stimulation: ACEI/ARBs also inhibit the effect of beta-adrenergic stimulation by enhancing myocardial nitric oxide production, which attenuates the positive inotropic effect of betaagonists $[43,44]$. Adrenergic receptor stimulation causes cardiomyocyte hypertrophy and subsequent development of HF mediated by G-proteincoupled receptor (GPCR) pathways [45,46]. The use of beta-blockers normalizes the GPCR function and enhance myocardial contractility [47]. Beta-blockers also normalizes the calcium signalling by regulating ryanodine receptor function leading to enhanced contractility [48].

\section{Electrophysiological processes}

Current evidence also points towards the involvement of electrophysiological processes in reverse ventricular remodelling in HFiEF patients. The gene expression profile of contractile proteins is altered in HFiEF patients who respond to CRT, with increased expression of $\alpha$-myosin heavy chain and phospholamban and decreased expression of $\beta$-myosin heavy chain $[49,50]$. CRT as well induces structural changes accompanied with restoration of normal T-tubule and ryanodine receptor organization in a canine model of HF with LBBB [51]. The presence of AF can also inhibit reverse remodelling. Restoration of sinus rhythm by catheter ablation may also result in higher rates of improvement of LVEF in HFrEF patients, which is less frequent in HFrEF patients on rate control alone [52,53]. Molecular mechanisms that underlie LVEF improvement remain unclear. However, whether by attenuation of abnormal neurohormonal and electrical activity, structural changes induced by HF regimens may help to explain the mechanisms of reverse remodelling.

\section{Clinical management}

\section{Current HF treatment}

Evidence-based management of HF relies almost entirely on findings from HFrEF patients, and is distinctly different from that provided to HFpEF patients (Table 3). A greater majority of the evidence supporting the use of HF medical therapy involves HFrEF patients. In particular, clinical trials demonstrating a reduction in mortality excluded HFpEF patients [54]. Thus, diagnosis and treatment of HF patients requires distinguishing the two most common HF phenotypes, which are core quality measure for HFiEF management.

Treatment of HFrEF, in the absence of contraindications, usually includes ACEI and beta-blockers, which are the key treatments 
Table 3. Treatment for HFrEF and HFpEF patients

\begin{tabular}{|c|c|c|}
\hline Treatment & $\begin{array}{l}\text { Indications for HFrEF } \\
\text { (Evidence supporting its use) }\end{array}$ & Indications for HFpEF (Evidence supporting its use) \\
\hline ACEI & All patients (reduces mortality) & No evidence \\
\hline B-blocker & All symptomatic patients (reduces mortality) & No evidence \\
\hline Aldosterone Antagonists & Rest dyspnoea, post-MI with DM/symptomatic HF (reduces mortality) & No evidence \\
\hline Nitrates & $\begin{array}{l}\text { African American Patients with persistence HF despite OMT/ intolerance to ACEI/ } \\
\text { ARBs due to renal insufficiency (reduces mortality) }\end{array}$ & No evidence \\
\hline Diuretics & As needed for fluid overload & As needed for fluid overload \\
\hline ARBs & Intolerance to ACEI due to cough/angioedema (reduces mortality) & Symptomatic patients (reduces hospitalization rates) \\
\hline Digoxin & Persistent symptoms despite background therapy, HF and AF (reduces mortality). & No evidence \\
\hline ICD & $\mathrm{EF}<35 \%$ and ischemic cardiomyopathy (reduces mortality). & No evidence \\
\hline
\end{tabular}

for HFrEF patients. Aldosterone antagonists may be indicated for HFrEF patients having or recently had rest dyspnoea. They are also indicated for HFrEF patients with 3 to 4 days post-MI and have DM or are asymptomtomatic. Indications for African Americans exhibiting persistent symptoms despite optimal medical therapy using ACEI, betablockers and diuretics are nitrates. ICD is also used in the treatment of HFrEF reduces the risk of death. On the other hand, treating HF with preserved LVEF (HFpEF) lacks sufficient evidence-based treatment because of a paucity of studies involving HFpEF patients. However, it is common for patients to use diuretics to control signs and symptoms of congestion. The CHARM-Preserved trial demonstrated the effectiveness of Candesartan - an ARB in reducing the rates of hospitalization among asymptomatic patients with a preserved LVEF.

\section{Challenges in HFiEF treatment}

The current guidelines provide recommendations for the treatment of HFrEF and HFpEF. However, the two treatment options do not clearly address the treatment of HFiEF patients due to differences in clinical and biochemical profiles. At present is it unclear whether HFiEF patients should continue with the HF medication regimen they followed when they improved their LVEF or they should receive medication regimen for HFpEF patients. Complicating the choice is the lack of studies investigating the impact of serial measurement of LVEF in HF patients. Only two small-sized studies indicated prognostic significance of serial LVEF measurement where the LVEF was improving but their reproducibility and clinical significant was not clear [55,56]. Both the $\mathrm{ACCF} / \mathrm{AHA}$, and the ESC HF guidelines recommend repeat LVEF measurement only when clinically indicated $[57,58]$.

The accuracy of serial LVEF measurement using echocardiography has several limitations. To date, echocardiography remains the most widespread used cardiac imaging modalities because it is fast, portable and non-invasive [54]. However, physiologic limitations and challenges of calculating a $3 \mathrm{D}$ parameter with $2 \mathrm{D}$ images limits the usefulness of echocardiography for the measurement of LVEF. The modality lacks the ability to reliably identify small changes or improvement in LVEF. Techniques such as contrast or radionuclide ventriculography can improve reliability but are more costly and invasive [59]. A systematic review comparing echocardiography with contrast or radionuclide ventriculography reported no method in general use to measure LVEF from echocardiographic images could provide a 95\% CI of changes of \pm 10 percentage points in the measurement of LVEF [60]. However, the American Society of echocardiography has published standards to improve measurement technique and minimize variability in LVEF measurement [61].

\section{Recurrence of reduced LVEF}

Treatment for HF usually considers reversible and non-reversible causes of HF. Treatment regimens such as diuretics, oxygen and other supportive therapies can reverse symptoms of congestion. Reversible aetiologic agents of HF include alcohol cardiotoxicity, thyroid disease, tachycardia, anaemia, valvular heart disease and coronary artery disease [54]. However, reversing symptoms does not necessarily imply the reversal of the HF itself. Besides, normalization of LVEF in HFiEF patients does not mean HF has been cured.

Moon et al. [40] studies the recovery and recurrence of LV systolic dysfunction in $42 \mathrm{HF}$ patients due to idiopathic DCM whose LVEF had normalized, increasing from a mean of $26 \%$ to $\geq 40 \%$ with an absolute increase of LVEF $\geq 10 \%$. During a follow-up period of 41 months and $19 \%$ of the patients experienced a reduction in LVEF, especially among patients who had discontinued HF medication. In a related prospective study, Cioffi et al. [62] followed $110 \mathrm{HFrEF}$ patients on guideline directed therapy, and reported $18 \%$ had normalized their LVEF during a 17 -months follow-up, but in $55 \%$ of the cases, the normalization was transient. COPD was a major determinant of the recurrence of HFrEF. In an Italian registry, prospective follow-up of 581 patients with DCM reported healing (reverse remodelling) in $16 \%$ of the patients in response to treatment with ACEI and beta-blockers. However, in the majority of the patients, the aetiologic agent remained [63].

\section{Continuation of HF treatment}

The benefits of whether to continue or discontinue HF therapy among HFiEF patients remains unclear. However, a recent clinical trial valuating the impact of the discontinuation of HF therapy in HFiEF patients associates it with recurrence of reduced LVEF [64]. Halliday et al. [64] examined the effect of phased withdrawal of HF medication in 51 patients with previous DCM but now asymptomatic - LVEF had improved from $<40 \%$ to $\geq 50 \%$, LVEDV had normalized and had $\mathrm{N}$-terminal pro-B-type natriuretic peptide levels $<250 \mathrm{ng} / \mathrm{L}$. twentyfive (25) were randomized to treatment withdrawal group and 26 to continued treatment group. In the first six months, $44 \%$ of the treatment withdrawal group experience a relapse of HF defined as reduction in LVEF $>10 \%$ and to $<50 \%$, while none of the treatment group has a relapse. After six months, 25 patients in the treatment group withdrew treatment and in the next six months, nine of them experienced a relapse. The study recommended continued HF treatment among HFiEF patients because of the high risk of relapse following treatment withdrawal. Until robust predictors of relapse are defines, HF treatment among HFiEF patients should continue indefinitely [64-66].

The recent study by Halliday et al. [64] have important clinical implications in the management of HFiEF patients. The study suggests that the mechanisms of LVEF improvement after adherence to guideline-directed HF regimens remain to be elucidated. Besides LVEF, biomarker and clinical profiles that align with treatment are lacking. There is no sign or feature to indicate that previously indicated HF treatment for reduced LVEF is no longer necessary and could be 
safely discontinued. Wilcox, and Yancy [65] suggest the need for a more precise nomenclature. HFiEF patients with restored LV function are less likely to have recovered (healed) ventricular function and more appropriately, they described them as having ventricular dysfunction in remission. The Halliday study [64] endorses the view that most HFiEF patients with improved ventricular function as measured by LVEF are in remission and have an indefinite indication for evidence-based HF treatment without interruption.

Normalization of ventricular function in HFiEF patients following exposure to guideline-directed therapy suggests the restoration of intrinsic contractility and cardiac mechanics assessed by Lagrangian strain, the normalization of protein expression and the restoration of neurohormonal milieu that is no longer activated. However, many HFiEF patients may still have underlying abnormal cardiac mechanics such as impaired longitudinal strain and remain at risk for clinical events and HF relapse, even with continued medical treatment. Thus, HFiEF patients who relapse may have abnormal strain whereas those who do not relapse have normal strain measurements. However, measurement of strain has not been standardized. For instance, feature tracking CMR methods have a much higher reported normal values.

\section{Conclusion}

HFiEF is a relatively recent description of a subset of HF patients. Its definition is not based on specific clinical, biomarker or structural features rather on the changes (improvement) of LVEF to normal values in patients with previously reduced LVEF. However, the precise definition of HFiEF is lacking with different studies providing different LVEF cut off values of $>40 \%,>45 \%,>50 \%$, or an increase of $>10 \%$. The lack of definitional uniformity undermines a holistic understanding of this HF phenotype. Nonetheless, HFiEF has important implications for the management of HF patients. They account for a significant percentage in HF referral population. They have more favourable clinical, biomarker and functional characteristics compared to HFrEF and HFpEF patients, but less favourable compared to healthy controls. Relative to HFrEF patients, HFiEF patients are younger, have a shorter HF duration, and have fewer comorbidities. Factors that predict LVEF improvement in HFrEF patients include the female sex, shorter duration of HF, den novo onset of HF, non-ischemic aetiology, NYHA functional class II-III, normal GLS (>16), and beta-blocker therapy. Diagnosis of HFiEF is based purely on the improvement or normalization of LVEF as measured by echocardiography. Clinical management remains a challenge since current guidelines only provide recommendation for HFrEF and HFpEF, which may not address the differences in clinical and biochemical profiles of HFiEF patients. Since the withdrawal of guideline-directed medical therapy increases the risk of relapse of reduced LVEF in a majority of patients, indefinite continuation of HF treatment is recommended until such a time when robust predictors of relapse have been defined.

\section{References}

1. Cohn JN, Archibald DG, Ziesche S, Franciosa JA, Harston WE, et al. (1986) Effect of vasodilator therapy on mortality in chronic congestive heart failure. N Engl J Med 314: 1547-1552. [Crossref]

2. Punnoose LR, Givertz MM, LewisEF, Pratibhu P, Stevenson LW, et al. (2011) Heart failure with recovered ejection fraction: a distinct clinical entity. J Card Fail 17: 527532. [Crossref]

3. McMurray JJ, Adamopoulos S, Anker SD, Auricchio A, Bohm M, et al. (2012) ESC Guidelines for the diagnosis and treatment of acute and chronic heart failure 2012: The Task Force for the Diagnosis and Treatment of Acute and Chronic Heart Failure 2012 of the European Society of Cardiology. Developed in collaboration with the Heart Failure Association (HFA) of the ESC. Eur J Heart Fail 14: 803-869. [Crossref]
4. Ponikowski P, Voors AA, Anker SD, Bueno H, Cleland JG, et al. (2016) 2016 ESC Guidelines for the diagnosis and treatment of acute and chronic heart failure: The Task Force for the diagnosis and treatment of acute and chronic heart failure of the European Society of Cardiology (ESC) Developed with the special contribution of the Heart Failure Association (HFA) of the ESC. Eur Heart J 37: 2129-2200. [Crossref]

5. Yancy CW, Jessup M, Bozkurt B, Butler J, Casey DE, et al. (2013) 2013 ACCF/AHA guideline for the management of heart failure: a report of the American College of Cardiology Foundation/American Heart Association Task Force on Practice Guidelines. $J$ Am Coll Cardiol 62: e147-e239. [Crossref].

6. McKelvie RS, Moe GW, Ezekowitz JA, Heckman GA, Costigan J, et al. (2013) The 2012 Canadian Cardiovascular Society heart failure management guidelines update: focus on acute and chronic heart failure. Can J Cardiol 29: 168-181. [Crossref]

7. Haddad F, Hunt SA, Rosenthal DN, Murphy DJ (2008) Right ventricular function in cardiovascular disease, part I: anatomy, physiology, aging, and functional assessment of the right ventricle. Circulation 117: 1436-1448. [Crossref]

8. Tanabe K, Sakamoto T (2019) Heart failure with recovered ejection fraction. Journal Echocardiogr 17: 5-9. [Crossref]

9. BasurayA, French B, Ky B, Vorovich E, Olt C, et al. (2014) Heart failure with recovered ejection fraction: clinical description, biomarkers, and outcomes. Circulation 129: 2380-2387. [Crossref]

10. Farré N, Lupon J, Roig E, Gonzalez-Costello J, Vil J, et al. (2017) Clinical characteristics, one-year change in ejection fraction and long-term outcomes in patients with heart failure with mid-range ejection fraction: a multicentre prospective observational study in Catalonia (Spain). BMJ Open 7: 1-9. [Crossref]

11. Bermejo RA, Babarro EG, Canoa JNL, Román AV, Otero IG, et al. (2018) Heart failure with recovered ejection fraction: clinical characteristics, determinants and prognosis. CARDIOCHUS-CHOP registry. Cardiol J 25: 353-362. [Crossref]

12. Chen X, Xin Y, Hu W, Zhao Y, Zhang Z, et al. (2019) Quality of life and outcomes in heart failure patients with ejection fractions in different ranges. PloS One, 14: e0218983. [Crossref]

13. Stevenson LW (2014) Heart failure with better ejection fraction: a modern diagnosis Circulation 129: 2364-2367. [Crossref]

14. Florea VG, Rector TS, Anand IS, Cohn JN (2016) Heart failure with improved ejection fraction: clinical characteristics, correlates of recovery, and survival: results from the Valsartan Heart Failure Trial. Circ Heart Fail 9: 1-6. [Crossref]

15. Gulati G, Udelson JE (2018) Heart Failure With Improved Ejection Fraction: Is it Possible to Escape One's Past? JACC: Heart Fail 6: 725-733. [Crossref]

16. Kramer DG, Trikalinos TA, Kent DM, Antonopoulos GV, Konstam MA, et al (2010) Quantitative evaluation of drug or device effects on ventricular remodeling as predictors of therapeutic effects on mortality in patients with heart failure and reduced ejection fraction: a metaanalytic approach. J Am Coll Cardiol 56: 392-406. [Crossref]

17. Rivera AMC (2016) Reversible left ventricular dysfunction: A review of risk factors, management and prognosis. In Lynch, Marvin (Ed), Takotsubo Cardiomyopathy, Middlesex, UK: Nova Science Publishers, Inc.

18. Sharkey SW, Lesser JR, Zenovich AG, Maron MS, Lindber J, et al. (2005) Acute and reversible cardiomyopathy provoked by stress in women from the United States. Circulation 111: 472-479. [Crossref]

19. Kawai S, Suzuki H, Yamaguchi H, Tanaka K, Sawada H, et al. (2000) Ampulla cardiomyopathy ('Takotusbo' cardiomyopathy) - Reversible left ventricular dysfunction: with ST segment elevation. Jpn Circ J 64: 156-159. [Crossref]

20. Givertz MM, Mann DL (2013) Epidemiology and natural history of recovery of left ventricular function in recent onset dilated cardiomyopathies. Curr Heart Fail Rep 10: 321-330. [Crossref]

21. Ruwald MH, Solomon SD, Foster E, Kutyifa V, Ruwald AC, et al. (2014) Lef ventricular ejection fraction normalization in cardiac resynchronization therapy and risk of ventricular arrhythmias and clinical outcomes: results from the Multicenter Automatic Defibrillator Implantation Trial With Cardiac Resynchronization Therapy (MADIT-CRT) trial. Circulation 130: 2278-2286. [Crossref]

22. Antonio N, Teixeira R, Coelho L, Lourenco C, Monteiro P, et al. (2009) Identification of 'super-responders' to cardiac resynchronization therapy: the importance of symptom duration and left ventricular geometry. Europace 11: 343-349. [Crossref]

23. Tian Y, Zhang P, Li X, Gao Y, Zhu T, et al. (2013) True complete left bundle branch block morphology strongly predicts good response to cardiac resynchronization therapy. Europace 15: 1499-1506. [Crossref] 
24. Cicoira M, Zanolla L, Latina L, Rossi A, Golia G, et al. (2001) Frequency, prognosis and predictors of improvement of systolic left ventricular function in patients with 'classical'clinical diagnosis of idiopathic dilated cardiomyopathy. Eur J Heart Fail 3: 323-330. [Crossref]

25. Wilcox JE, Fonarow GC, Yancy CW, Albert NM, Curtis AB, et al. (2012) Factors associated with improvement in ejection fraction in clinical practice among patients with heart failure: findings from IMPROVE HF. Am Heart $J$ 163: 49-56. [Crossref]

26. De Groote P, Fertin M, Duva Pentiah A, Goéminne C, Lamblin N, et al. (2014) Longterm functional and clinical follow-up of patients with heart failure with recovered left ventricular ejection fraction after $\beta$-blocker therapy. Circ Heart Fail 7: 434-439. [Crossref]

27. Kalogeropoulos AP, Fonarow GC, Georgiopoulou V, Burkman G, Siwamogsatham S, et al. (2016) Characteristics and outcomes of adult outpatients with heart failure and improved or recovered ejection fraction. JAMA Cardiology 1: 510-518. [Crossref]

28. Nadruz Jr W, West E, Santos M, Skal H, Groarke JD, et al. (2016) Heart failure and midrange ejection fraction: implications of recovered ejection fraction for exercise tolerance and outcomes. Circ Heart Fail 9: 1-17. [Crossref]

29. Trullas JC, Manzano L, Formiga F, Aramburu-Bodas O, Quesada-Simón MA, et al. (2016) Heart failure with recovered ejection fraction in a cohort of elderly patients with chronic heart failure. Cardiol 135: 196-201. [Crossref]

30. Adamo L, Perry A, Novak E, Makan M, Lindman BR, Mann DL (2017) Abnormal global longitudinal strain predicts future deterioration of left ventricular function in heart failure patients with a recovered left ventricular ejection fraction. Circ Heart Fail 10: e003788. [Crossref]

31. Lupon J, Díez-López C, de Antonio M, Domingo M, Zamora E, et al. (2017) Recovered heart failure with reduced ejection fraction and outcomes: a prospective study. Eur $J$ Heart Fail 19: 1615-1623. [Crossref]

32. Swat SA, Cohen D, Shah SJ, Lloyd-Jones DM, Baldridge AS, et al. (2018) Baseline Longitudinal Strain Predicts Recovery of Left Ventricular Ejection Fraction in Hospitalized Patients With Nonischemic Cardiomyopathy. J Am Heart Assoc 7: e09841. [Crossref]

33. Park CS, Park JJ, Mebazaa A, Oh IY, Park HA, et al. (2019). Characteristics, Outcomes, and Treatment of Heart Failure With Improved Ejection Fraction. J Am Heart Assoc 8: e011077. [Crossref]

34. Rigolli M, Cicoira M, Bergamini C, Chiampan A, Rossi A, et al. (2011) Progression of left ventricular dysfunction and remodelling under optimal medical therapy in CHF patients: role of individual genetic background. Cardiol Res Pract 2011: 1-6. [Crossref]

35. Jansweijer JA, Nieuwhof K, Russo F (2017) Truncating titin mutations are associated with a mild and treatable form of dilated cardiomyopathy. Eur J Heart Fail 19: 512521. [Crossref]

36. Ware JS, Li J, Mazaika E (2016) Shared genetic predisposition in peripartum and dilated cardiomyopathies. $N$ Engl J Med 374: 233-241. [Crossref]

37. Merlo M, Pyxaras SA, Pinamonti B, Barbati G, Di Lenarda A, et al. (2011) Prevalence and prognostic significance of left ventricular reverse remodeling in dilated cardiomyopathy receiving tailored medical treatment. J Am Coll Cardiol 57: 14681476. [Crossref]

38. Udelson JE, Konstam MA (2011) Ventricular remodeling: fundamental to the progression (and regression) of heart failure. J Am Coll Cardiol 57: 1477-1479. [Crossref]

39. Park JS, Kim JW, Seo KW (2014) Recurrence of left ventricular dysfunction in patients with restored idiopathic dilated cardiomyopathy. Clin Cardiol 37: 222-226. [Crossref]

40. Moon J, Ko Y-G, Chung N (2009) Recovery and recurrence of left ventricular systolic dysfunction in patients with idiopathic dilated cardiomyopathy. Can J Cardiol 25: e147-e150. [Crossref]

41. Gray MO, Long CS, Kalinyak JE, Li HT, Karliner JS (1998) Angiotensin II stimulates cardiac myocyte hypertrophy via paracrine release of TGF- $\beta 1$ and endothelin- 1 from fibroblasts. Cardiovasc Res 40: 352-363. [Crossref]

42. Hale TM (2016) Persistent phenotypic shift in cardiac fibroblasts: impact of transient renin angiotensin system inhibition. J Mol Cell Cardiol 93: 125-132. [Crossref]

43. Wittstein IS, Kass DA, Pak PH, Maughan WL, Fetics B, et al. (2001) Cardiac nitric oxide production due to angiotensin-converting enzyme inhibition decreases betaadrenergic myocardial contractility in patients with dilated cardiomyopathy. $J$ Am Coll Cardiol 38: 429-435. [Crossref]

44. Hare JM, Loh E, Creager MA, Colucci WS (1995) Nitric oxide inhibits the positive inotropic response to beta-adrenergic stimulation in humans with left ventricular dysfunction. Circulation 92: 2198-2203. [Crossref]
45. D’Angelo DD, Sakata Y, Lorenz JN (1997) Transgenic Galphaq overexpression induces cardiac contractile failure in mice. Proc Natl Acad Sci USA 94: 8121-8126. [Crossref]

46. Engelhardt S, Hein L, Wiesmann F, Lohse MJ (1999) Progressive hypertrophy and heart failure in beta1-adrenergic receptor transgenic mice. Proc Natl Acad Sci USA 96: 7059-7064. [Crossref]

47. Bohm M, Deutsch HJ, Hartmann D, La Rosee K, Stablein A (1997) Improvement of post-receptor events by metoprolol treatment in patients with chronic heart failure. $J$ Am Coll Cardiol 30: 992-996. [Crossref]

48. Reiken S, Wehrens XHT, Vest JA (2003) Beta-blockers restore calcium release channel function and improve cardiac muscle performance in human heart failure. Circulation 107: 2459-2466. [Crossref]

49. Iyengar S, Haas G, Lamba S (2007) Effect of cardiac resynchronization therapy on myocardial gene expression in patients with non-ischemic dilated cardiomyopathy. $J$ Card Fail 13: 304-311. [Crossref]

50. Vanderheyden M, Mullens W, Delrue L (2008) Myocardial gene expression in heart failure patients treated with cardiac resynchronization therapy responders versus nonresponders. J Am Coll Cardiol 51: 129-136. [Crossref]

51. Sachse FB, Torres NS, Savio-Galimberti E (2012) Subcellular structures and function of myocytes impaired during heart failure are restored by cardiac resynchronization therapy. Circ Res 110: 588-597. [Crossref]

52. Hunter RJ, Berriman TJ, Diab I (2014) A randomized controlled trial of catheter ablation versus medical treatment of atrial fibrillation in heart failure (the CAMTAF trial). Circ Arrhythm Electrophysiol 7: 31-38. [Crossref]

53. Prabhu S, Taylor AJ, Costello BT (2017) Catheter ablation versus medical rate control in atrial fibrillation and systolic dysfunction: the CAMERAMRI study. $J \mathrm{Am} \mathrm{Coll}$ Cardiol 70: 1949-1961. [Crossref]

54. Chavey WE (2010) Ejection fraction is back to normal--now what? Heart failure treatment guidelines don't address whether to change a patient's medications should the EF improve. This evidence review provides guidance. J Fam Pract 59: 142-147. [Crossref]

55. Moreo A, De Chiara B, Cataldo G, Piccalò G, Lobiati E, et al. (2006). Prognostic value of serial measurements of left ventricular function and exercise performance in chronic heart failure. Rev Esp Cardiol 59: 905-910. [Crossref]

56. Metra M, Nodari S, Parrinello G, Giubbini R, Manca C, et al. (2003) Marked improvement in left ventricular ejection fraction during long-term $\beta$-blockade in patients with chronic heart failure: clinical correlates and prognostic significance. $\mathrm{Am}$ Heart J 145: 292-299. [Crossref]

57. Dickstein K, Cohen-Solal A, Filippatos G, McMurray JJ, Ponikowski P, et al. (2008) ESC Guidelines for the diagnosis and treatment of acute and chronic heart failure 2008: The Task Force for the Diagnosis and Treatment of Acute and Chronic Heart Failure 2008 of the European Society of Cardiology. Developed in collaboration with the Heart Failure Association of the ESC (HFA) and endorsed by the European Society of Intensive Care Medicine (ESICM). Eur J Heart Fail 10: 933-989. [Crossref]

58. Swedberg K, Cleland J, Dargie H, Drexler H, Follath F, et al. (2005) Guidelines for the diagnosis and treatment of chronic heart failure: executive summary (update 2005) The Task Force for the Diagnosis and Treatment of Chronic Heart Failure of the European Society of Cardiology. Eur Heart J 26: 1115-1140. [Crossref]

59. Malm S, Frigstad S, Sagberg E, Larsson H, Skjaerpe T (2004) Accurate and reproducible measurement of left ventricular volume and ejection fraction by contras echocardiography: a comparison with magnetic resonance imaging. $J$ Am Coll Cardiol 44: 1030-1035. [Crossref]

60. McGowan JH, Cleland JG (2003) Reliability of reporting left ventricular systolic function by echocardiography: a systematic review of 3 methods. Am Heart $J$ 146: 388-397. [Crossref]

61. Lang RM, Bierig M, Devereux RB, Flachskampf FA Foster E, et al. (2006) Recommendations for chamber quantification. Eur $J$ Echocardiogr 7: 79-108 [Crossref]

62. Cioffi G, Stefenelli C, Tarantini L,Opasich C (2004) Chronic left ventricular failure in the community: prevalence, prognosis, and predictors of the complete clinical recovery with return of cardiac size and function to normal in patients undergoing optima therapy. J Card Fail 10: 250-257. [Crossref]

63. Di Lenarda A, Sabbadini G, Perkan A, Carniel E, Pangher S, et al. (2001) Apparent healing in dilated cardiomyopathy: incidence, long-term persistence and predictive factors. The heart muscle disease registry of Trieste. Ital Heart J Suppl 5: 253-256. [Crossref] 
Albakri A (2020) Heart failure with improved ejection fraction: A review and pooled analysis of pathophysiology, diagnosis and clinical management

64. Halliday BP, Wassall R, Lota AS, Khalique Z, Gregson J, Newsome S, et al. (2019) Withdrawal of pharmacological treatment for heart failure in patients with recovered dilated cardiomyopathy (TRED-HF): an open-label, pilot, randomised trial. Lancet 393: 61-73. [Crossref]
65. Wilcox J, Yancy CW (2019) Stopping medication for heart failure with improved ejection fraction. Lancet 393: 8-10. [Crossref]

66. Psaty BM, Shah SJ Gottdiener J (2015) Letter by Psaty et al regarding article, Heart failure with recovered ejection fraction: clinical description, biomarkers, and outcomes. Circulation 131: e343-e343. [Crossref]

Copyright: (C2020 Albakri A. This is an open-access article distributed under the terms of the Creative Commons Attribution License, which permits unrestricted use, distribution, and reproduction in any medium, provided the original author and source are credited. 